\title{
Molecular Modeling of Vanadium-Oxo Complexes. A Comparison of Quantum and Classical Methods
}

\author{
Thomas R. Cundari,* Leah Saunders, and Laura L. Sisterhen \\ Department of Chemistry, University of Memphis, Memphis, Tennessee 38152-6060
}

Received: August 29, 1997; In Final Form: November 10, 1997

\begin{abstract}
A force field for vanadium-oxos was developed and tested with a variety of complexes with coordination numbers of 5 or 6 and formal oxidations states of +4 or +5 on the metal. Similarly, a semiempirical quantum mechanical method for transition metals was extended to vanadium. In this research soft and hard ligands were studied, as were ligands coordinated through single, multiple, and dative bonds. Despite the diversity of vanadium coordination chemistry, generally good modeling is achieved in a fraction of the time with less computational resources using molecular mechanics and semiempirical quantum mechanics. $\mathrm{The}_{4} \mathrm{~L}^{4+} \mathrm{O}$ and $\mathrm{L}_{5} \mathrm{~V}^{5+} \mathrm{O}$ groups were emphasized given their prevalence and importance. In general, the predictive ability was superior for the former structural motif. The combination of molecular mechanics and semiempirical quantum calculations provide an effective and efficient tool for analysis of the steric and electronic energy differences between isomers.
\end{abstract}

\section{Introduction}

Complexes with a vanadium-oxo moiety occupy an important place in inorganic chemistry. Indeed, this group is one of the most ubiquitous. Vanadium-oxos have been the subject of much experimental study and have been studied for applications ranging from catalysis to biomedical applications. Coulston and co-workers have recently identified $\mathrm{V}^{5+}$ complexes as key intermediates in the oxidation of $n$-butane to maleic anhydride by $(\mathrm{VO})_{2} \mathrm{P}_{2} \mathrm{O}_{7}$ or $\mathrm{VOPO}_{4} .^{1}$ Researchers have demonstrated that vanadate and vanadyl $\left(\mathrm{VO}^{2+}\right)$ ions mimic insulin activity in vitro. More recently, oral vanadate therapy on experimental models of noninsulin-dependent diabetes mellitus (NIDDM) induced long and persistent states of normoglycemia, ${ }^{2}$ although the mode of action for lowering blood glucose in diabetic rats is not well understood. Research does suggest that the form responsible for the insulin-mimetic effect is vanadyl. ${ }^{3}$ Their distinctive and sensitive spectra has led to them being widely used as experimental probes of molecular structure and dynamics. $^{4}$

Vanadium-oxos possess a chemical diversity that is challenging to modeling. Molecular mechanics (MM) has not been widely applied to vanadium complexes. Previous research has focused on modeling a subset of $\mathrm{V}$-oxos, i.e., those with peroxide coligands. Very good agreement was found between the MM-predicted and experimental structures. ${ }^{5}$ We now seek to extend this research to a wider array of $\mathrm{V}-$ oxos and to compare with the results obtained using the PM3 semiempirical Hamiltonian. ${ }^{6}$ Researchers have found the challenges in MM modeling of metals to include development of MM parameters (given the paucity of experimental data available for this purpose) and the chemical diversity of transition metals. ${ }^{7}$ Researchers have shown that quantum calculations can be used to estimate MM parameters with sufficient accuracy for developing metal force fields. ${ }^{5,7 b, 8}$ The extent to which MM parameters can be transferred from one complex to another (e.g., the $\mathrm{V}$-oxo bond in $\mathrm{V}^{5+}$ vs $\mathrm{V}^{4+}$ complexes) or even within a complex (e.g., $\mathrm{V}-\mathrm{O}_{\text {cis }} \mathrm{vs} \mathrm{V}-\mathrm{O}_{\text {trans }}$ in $\left[\mathrm{VO}\left(\mathrm{OH}_{2}\right)_{5}\right]^{2+}$ ) remains an important issue to be addressed. For this reason, vanadiumoxos constitute an attractive choice of target complexes.

\section{Computational Methods}

Quantum Mechanics. Ab initio quantum mechanical calculations employed the GAMESS program. ${ }^{9}$ Effective core potentials (ECPs) and valence basis sets (VBSs) were used for heavy atoms and the $-31 \mathrm{G}$ basis set for $\mathrm{H}$. ECPs replace the innermost core orbitals for vanadium and all core orbitals for main-group (MG) elements. ${ }^{10}$ Thus, the $3 \mathrm{~s}, 3 \mathrm{p}, 3 \mathrm{~d}, 4 \mathrm{~s}$, and $4 \mathrm{p}$ orbitals were treated explicitly for vanadium; ${ }^{10}$ for main-group elements, $n$ s and $n$ p orbitals were treated explicitly. ${ }^{10}$ The vanadium VBS was quadruple- and triple- $\zeta$ for the sp and $d$ shells, respectively, while MG elements had double- $\zeta$-pluspolarization VBSs. ${ }^{10}$ This scheme has been widely applied to transition metal chemistry. ${ }^{11}$ Geometries were optimized at the restricted Hartree-Fock level for closed-shell singlets. Vibrational frequencies were calculated at all stationary points to identify them as minima and to obtain the necessary metalligand force constants. ${ }^{12}$

Geometry optimization utilizing semiempirical quantum theory were performed using the Spartan package (version 4.1.2) and the PM3 Hamiltonian developed to describe d-block metals. ${ }^{6}$ PM3 parameters for vanadium were obtained by simple interpolation of parameters for the metals flanking it in the periodic table-titanium and chromium.

Molecular Mechanics. The force field included the following terms, eq $1 .^{13}$ The steric energy, $U_{\text {steric }}$, of a complex is the

$$
U_{\text {steric }}=\sum U_{\mathrm{s}}+\sum U_{\mathrm{b}}+\sum U_{\mathrm{t}}+\sum U_{\mathrm{vdW}}
$$

sum of individual bond stretching, $U_{\mathrm{s}}$; angle bending, $U_{\mathrm{b}}$; bond torsion, $U_{\mathrm{t}}$; and van der Waals interactions, $U_{\mathrm{vdW}}$. A steepest descent algorithm was used for geometry optimization; ${ }^{14}$ optimizations were carried out until the root-mean-square deviation (RMS) gradient was $\leq 0.002 \mathrm{kcal}^{-1}$. Calculations employed harmonic $U_{\mathrm{s}}$ and $U_{\mathrm{b}}$ potentials and neglected stretch- 
TABLE 1: New MM Atom Type Parameters ${ }^{a}$

\begin{tabular}{lccccc}
\hline \multicolumn{1}{c}{ atom type } & atom type no. & $R^{*}$ & $\epsilon$ & at. wt & lone pairs \\
\hline O oxide & 77 & 1.740 & 0.066 & 15.995 & 0 \\
O coord water & 85 & 1.740 & 0.050 & 15.995 & 0 \\
O coord carboxylate & 86 & 1.740 & 0.050 & 15.995 & 0 \\
S coord thiolate & 162 & 1.910 & 0.202 & 31.972 & 0 \\
V SQP5 & 239 & 2.847 & 0.200 & 50.944 & 1 \\
N coord imine & 800 & 1.820 & 0.055 & 14.003 & 0 \\
O coord alkoxide & 808 & 1.740 & 0.066 & 15.995 & 0 \\
O coord enolate & 809 & 1.740 & 0.066 & 15.995 & 0 \\
N coord amine & 888 & 1.820 & 0.055 & 14.003 & 0
\end{tabular}

${ }^{a}$ This table gives the new atom type numbers for the force field developed in this research. $R^{*}$ is the van der Waals radius of the atom in angstroms; $\epsilon$ is the "hardness parameter" in $\mathrm{kcal} \mathrm{mol}^{-1}$. Atomic weight is reported in amu. Lone pairs denotes the number of lone pair pseudoatoms (atom type $=20$ ) attached to that atom type.

bend terms. Torsional potentials were described with a standard, three-term Fourier series expansion. The vdW terms were calculated by a Buckingham potential.

Fifty or more conformations were generated using molecular dynamics (MD) for each complex depending on its conformational flexibility. The complex was heated ( $2 \mathrm{fs}$ time steps) to $1000 \mathrm{~K}$ at a rate of $2.0 \mathrm{kcal}_{\text {atom }}^{-1} \mathrm{ps}^{-1}$. Conformations were sampled every 1 ps and then geometry-optimized using a twostep protocol. First, geometries were loosely MM-optimized (RMS gradient $\leq 0.025 \mathrm{kcal} \AA^{-1}$ ). Second, unique conformations were then MM-optimized with standard tight convergence criterion (RMS gradient $\leq 0.002 \mathrm{kcal} \AA^{-1}$ ). A similar conformational search protocol was used in the analysis of vanadiumoxo-peroxides. ${ }^{5}$ All MM optimizations were carried out on a Macintosh Quadra 800.

\section{Results and Discussion}

1. Force Field Derivation. The vanadium - oxos studied can be categorized by coordination number (C.N.) and formal oxidation state of the vanadium: C.N. $=5, \mathrm{~V}^{5+}$; C.N. $=6$, $\mathrm{V}^{4+}$; C.N. $=5, \mathrm{~V}^{4+}$; C.N. $=6, \mathrm{~V}^{5+}$. Another important subset of vanadium-oxos, i.e., those with peroxide coligands (generally having C.N. $=7, \mathrm{~V}^{5+}$ ) have been discussed previously. ${ }^{5}$ In general, ancillary ligands for vanadium-oxos were oxygen and nitrogen donor ligands, Table 1. Typically, $\mathrm{V}-$ oxo complexes $\left(\mathrm{L}_{n} \mathrm{VO}\right)$ with four ancillary ligands $(n=4)$ are square pyramidal while complexes with five ancillary ligands $(n=5)$ are octahedral.

There are two types of force field parameters needed to describe a coordination complex: metal-dependent and metalindependent. For metal-independent parameters, standard MM2 parameters were used. ${ }^{13}$ Derivation of metal-dependent parameters is outlined below. A table of new parameters is available as Supporting Information.

van der Waals. The van der Waals parameters for ligating atoms were taken from corresponding nonligating atom types. The same van der Waals radius $\left(R^{*}=2.847 \AA\right)$ and "hardness parameter" $\left(\epsilon=0.200 \mathrm{kcal} \mathrm{mol}^{-1}\right)$ were used for all vanadium atom types.

Bond Stretching. Equilibrium bond lengths and force constants for $\mathrm{V}$-ligand bonds were estimated from quantum calculations on model compounds: $C_{2 v}, \mathrm{VO}_{2} \mathrm{~F}_{2} ; C_{3 v}, \mathrm{VOF}_{3} ; C_{2 v}$, $\left[\mathrm{VO}_{2} \mathrm{~F}_{4}\right]^{2-} ; C_{1}, \mathrm{~V}(=\mathrm{NH})_{2}\left(\mathrm{NH}_{3}\right)\left(\mathrm{CH}_{3}\right)$. Methods used in quantum calculations are outlined above and described in detail elsewhere. ${ }^{11}$ X-ray data and ECP-based quantum calculations were used in estimation of $\mathrm{V}$-ligand equilibrium bond lengths.

Angle Bending. There are two types of metal-dependent, angle-bending potentials, $\mathrm{X}-\mathrm{V}-\mathrm{Y}$ and $\mathrm{V}-\mathrm{X}-\mathrm{Y}$. The former are replaced by 1,3-van der Waals $\left(U_{1,3}\right)$ interactions. $^{7 \mathrm{a}, \mathrm{e}}$ The latter were estimated from organic analogues (e.g., $\mathrm{C}_{\text {alkane }}-\mathrm{X}-$ $\mathrm{Y})$ and modified as needed. The efficacy of replacing $U_{\mathrm{b}}$ potentials with $U_{1,3}$ terms for high-coordination metals has been addressed. $^{7 \mathrm{a}, 15}$ Alternative approaches have been investigated. ${ }^{7 \mathrm{~b}}$

A lone pair pseudoatom was attached to $\mathrm{V}$ for square pyramidal complexes (atom type $=239$ ). Given the use of $U_{1,3}$ terms to describe $\mathrm{X}-\mathrm{V}-\mathrm{Y}$ angles, this pseudoatom keeps $\mathrm{L}_{4}{ }^{-}$ VO complexes from assuming a trigonal bipyramidal geometry. There are two structural isomers depending on whether the lone pair is cis (1a) or trans (1b) to the oxo. The latter is consistent with most structural data for $\mathrm{L}_{4} \mathrm{VO}$, particularly for $\mathrm{V}^{4+}$ complexes.

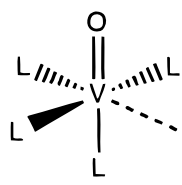

1a

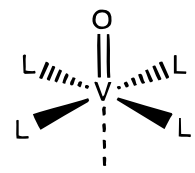

$1 \mathrm{~b}$
Torsion. There are two varieties of metal-dependent torsions: $\mathrm{X}-\mathrm{Y}-\mathrm{Z}-\mathrm{V}$ and $\mathrm{X}-\mathrm{Y}-\mathrm{V}-\mathrm{Z}$. The latter involve rotation about metal-ligand bonds and are often assumed to be small and set to zero. ${ }^{7 e}$ The former were approximated by assuming the metal plays a spectator role in determining the torsional potential about the $\mathrm{X}-\mathrm{Y}$ bond; $\mathrm{V}-\mathrm{X}-\mathrm{Y}-\mathrm{Z}$ torsional potentials are estimated from $\mathrm{C}_{\text {alkane }}-\mathrm{X}-\mathrm{Y}-\mathrm{Z}$ potentials. ${ }^{7 \mathrm{e}}$

2. Prediction of Lowest Energy Conformations. In this section each group of vanadium-oxos will be described according to formal oxidation state and coordination number. The $\mathrm{L}_{4} \mathrm{~V}^{4+} \mathrm{O}$ and $\mathrm{L}_{5} \mathrm{~V}^{5+} \mathrm{O}$ groups were emphasized given their prevalence in vanadium-oxo chemistry, the large numbers of structurally characterized examples available for validation of the computational methods, and their importance in catalysis and biochemistry.

2.1. Coordination Number 5, Oxidation State 5+. $\mathrm{V}^{5+-}$ oxos with coordination number 5 are typically dioxos, although $\mathrm{V}^{5+} \mathrm{OX}_{3} \mathrm{~B}(\mathrm{X}=$ monovalent anion such as a halide; $\mathrm{B}=$ neutral Lewis base) complexes are known. ${ }^{16}$ For example, of the 17 examples of this motif in the compendium by Nugent and Mayer, 13 are dioxos; the remaining examples are $\mathrm{V}^{5+} \mathrm{OCl}_{3}$ (NCR) complexes. ${ }^{16}$

The structure of $\mathrm{Cs}^{+}\left[\mathrm{V}^{5+}(\mathrm{O})_{2}(\mathrm{dpc})\right]^{-} \cdot \mathrm{H}_{2} \mathrm{O}$ has been reported, $\mathrm{dpc}=2,6$-pyridine-dicarboxylate. ${ }^{17}$ An MM/MD search $(50$ conformations) yielded a single unique conformation: a distorted trigonal bipyramid (TBP) with the coordinated carboxylate oxygens in axial positions $\left(E_{\text {steric }}=7.24 \mathrm{kcal} \mathrm{mol}^{-1}\right)$. The MM geometry was consistent with experiment. The root-meansquare deviation in inner coordination sphere atomic positions (i.e., vanadium and ligating atoms), $\mathrm{RMS}_{\mathrm{ic}}$, was $0.13 \AA$. Likewise, for the entire anion the root-mean-square deviation in all heavy atom positions, $\mathrm{RMS}_{\mathrm{hvy}}$, was $0.11 \AA$. Hydrogen atoms were not included in this and subsequent comparisons since they are typically not accurately located in X-ray diffraction. The overlay between the MM-predicted and X-ray structures for $\left[\mathrm{V}^{5+}(\mathrm{O})_{2}(\mathrm{dpc})\right]^{-}$is shown in Figure 1.

The crystal structure of $\left(\mathrm{NH}_{4}{ }^{+}\right)_{2}\left[\mathrm{~V}^{5+}(\mathrm{O})_{2}(\mathrm{~F})(\text { oxalate })\right]^{2-}$ has been reported. ${ }^{18}$ As with $\left[\mathrm{V}^{5+}(\mathrm{O})_{2}(\mathrm{dpc})\right]^{-}$, an MM/MD search (51 conformations) yielded one unique isomer with a distorted TBP geometry. The fluoride and an oxalate oxygen are axially coordinated while the oxos and the other oxalate oxygen are equatorial. Agreement between the MM and X-ray structures was very good: $\mathrm{RMS}_{\mathrm{ic}}=0.15 \AA \mathrm{RMS}_{\mathrm{hvy}}=0.13 \AA$. 


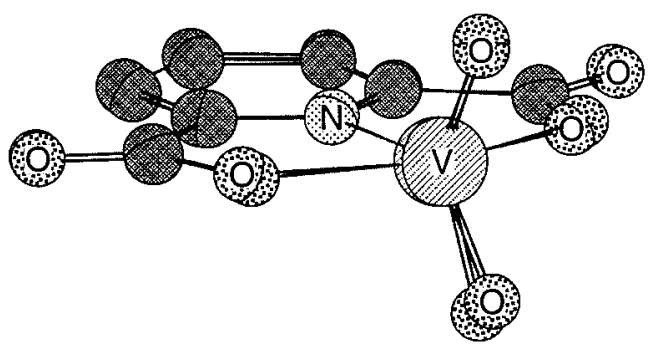

Figure 1. Overlay of MM-predicted and X-ray structures of $\left[\mathrm{V}^{5+}(\mathrm{O})_{2}(\mathrm{dpc})\right]^{-}$.

2.2. Coordination Number 6, Oxidation State 4+. The structure of $\left[\mathrm{V}^{4+} \mathrm{O}\left(\mathrm{OH}_{2}\right)_{5}\right]^{2+}\left[\mathrm{SO}_{4}\right]^{2-}$ has been reported ${ }^{19}$ and this complex shown to be important for diabetes treatment. ${ }^{2,3}$ A search of 50 conformations for the dication found all conformers to possess pseudo-octahedral geometry around $\mathrm{V}^{4+}$ differing only in proton positions. All conformers possessed similar steric energies covering a range of only $0.1 \mathrm{kcal} \mathrm{mol}^{-1}$. Reasonable modeling of the geometry was achieved although metal-ligand bonds proved to be challenging due to the oxo's strong trans influence. One could opt for a model with separate cis and trans aqua ligating types although this would require more extensive parametrization and result in a loss of generality. Accurate modeling of the trans influence was problematic even for high-level quantum methods. ${ }^{20}$ The $\mathrm{V}=\mathrm{O}$ bond in $\left[\mathrm{V}^{4+} \mathrm{O}\right.$ $\left.\left(\mathrm{OH}_{2}\right)_{5}\right]^{2+}$ was predicted to be $1.61 \AA$, as compared to $1.59 \AA$ in the crystal structure. ${ }^{19}$ The $\mathrm{V}-\mathrm{O}_{\text {trans }}$ bond was $2.05 \AA$ for the lowest energy $\mathrm{MM}$ structure $\left(2.21 \AA\right.$, expt); $\mathrm{V}-\mathrm{O}_{\text {cis }}$ bonds demonstrated a much smaller discrepancy: $2.05 \AA$ (MM); 2.02$2.03 \AA$ (expt.). This was due to the equilibrium bond length for $\mathrm{V}-\mathrm{O}_{\text {aqua }}$ being $2.03 \AA$, a compromise among $\mathrm{V}-\mathrm{O}_{\text {aqua }}$ bonds in $\mathrm{V}-$ oxos of varying oxidation state and coordination number. The force field also predicted the bending of cis waters away from the oxo and toward the trans aqua. The experimental $\mathrm{O}=\mathrm{V}-\mathrm{O}_{\text {cis }}$ angles were $96-100^{\circ}$ compared to $96^{\circ}$ in the predicted structure; $\mathrm{O}_{\text {trans }}-\mathrm{V}-\mathrm{O}_{\text {cis }}$ angles were $78-86^{\circ}$ experimentally $\left(84^{\circ}, \mathrm{MM}\right)$. Furthermore, $\mathrm{RMS}_{\mathrm{ic}}=\mathrm{RMS}_{\mathrm{hvy}}=0.10$ $\AA, 2$ (hydrogen atoms omitted from the figure for clarity), for the lowest energy MM structure.

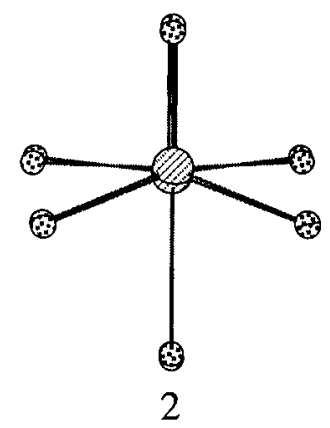

Another complex with the $\mathrm{L}_{5} \mathrm{~V}^{4+} \mathrm{O}$ structural motif is $\left.\left(\mathrm{Na}^{+}\right)_{3}\left[\mathrm{~V}^{4+} \mathrm{O} \text { (oxalate }\right)_{2}(\mathrm{~F})\right]^{3-} \cdot 6 \mathrm{H}_{2} \mathrm{O} .^{21}$ Quick inspection of this system immediately suggests two isomers, with the fluoride and oxo ligands either trans or cis. As a simple test of the MM/ MD simulated annealing approach used in this research, two separate conformational searches were performed starting from either the cis or the trans isomer. It is satisfying that both MD searches find the same two structural isomers. The cis isomer $\left(E_{\text {steric }}=8.76 \mathrm{kcal} \mathrm{mol}^{-1}\right)$ was predicted to be more stable than the trans isomer $\left(E_{\text {steric }}=9.32 \mathrm{kcal} \mathrm{mol}^{-1}\right)$, consistent with the experimental structure. cis- $\left[\mathrm{V}^{4+} \mathrm{O}(\text { oxalate })_{2}(\mathrm{~F})\right]^{3-}$ also showed excellent theory-experiment agreement in terms of the geometry: $\mathrm{RMS}_{\mathrm{ic}}=0.10 \AA, \mathrm{RMS}_{\mathrm{hvy}}=0.15 \AA$.
Two crystallographic forms (orthorhombic and anorthic) of $\left[\mathrm{V}^{4+}(\mathrm{O})(\mathrm{dpc})\left(\mathrm{OH}_{2}\right)_{2}\right] \cdot 2 \mathrm{H}_{2} \mathrm{O}$ have been reported. ${ }^{22}$ When overlaid, the $\mathrm{RMS}_{\mathrm{hvy}}$ value for the two experimental structures was $0.06 \AA$. Our comparison was with the newer structure. ${ }^{22 b}$ An MD search of 50 conformers (starting from either $\mathbf{3 a}$ or $\mathbf{3 b}$ )<smiles>OC12OCC(CO1)[N+]2(O)O</smiles>

$3 a$

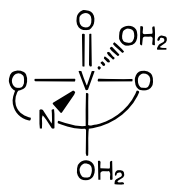

$3 b$ found two low-energy structures: trans di(aqua) (3a, $E_{\text {steric }}=$ $\left.6.78 \mathrm{kcal} \mathrm{mol}^{-1}\right)$ and trans oxo(aqua) $\left(3 \mathrm{~b}, E_{\text {steric }}=7.48 \mathrm{kcal}\right.$ $\left.\mathrm{mol}^{-1}\right)$. The lower steric energy for $\mathbf{3 a}\left(\mathrm{RMS}_{\mathrm{ic}}=0.06 \AA\right.$, $\mathrm{RMS}_{\mathrm{hvy}}=0.08 \AA$ ) was consistent with experimental structures $\left(\mathrm{RMS}_{\mathrm{hvy}}=1.01 \AA\right.$ for $\mathbf{3 b}$ and experiment $)$. INDO calculations ${ }^{23}$ (at MM geometries) also supported an electronic preference for 3a over $\mathbf{3 b}$ by $12 \mathrm{kcal} \mathrm{mol}^{-1}$.

2.3. Coordination Number 5, Oxidation State 4+. Perhaps the most common and most widely studied vanadiumoxos fall under this category. In addition to being structurally favorable, research has demonstrated that it is the $4+$ oxidation state of vanadium that effectively promotes glucose uptake and other insulin mimetic functions. ${ }^{2,3}$ Furthermore, vanadyl complexes are widely used as structural probes of catalyst and enzyme active sites. ${ }^{4}$

The crystal structure of $(\mathrm{Na})^{+}\left(\mathrm{NMe}_{4}\right)^{+}\left[\mathrm{V}^{4+} \mathrm{O}\left(\mathrm{SCH}_{2} \mathrm{CH}_{2}-\right.\right.$ $\left.\mathrm{S})_{2}\right]^{2-} \cdot \mathrm{EtOH}$ has been reported. ${ }^{24}$ Fifty conformations found by the MM/MD simulated annealing approach were searched. Two nearly degenerate isomers were observed depending on whether the $\mathrm{C}-\mathrm{C}$ bonds of the ethylene spacer were parallel $\left(\mathbf{4 a}, E_{\text {steric }}=4.2380 \mathrm{kcal} \mathrm{mol}^{-1}\right)$ or crossed $\left(\mathbf{4 b}, E_{\text {steric }}=4.2383\right.$ $\left.\mathrm{kcal} \mathrm{mol}^{-1}\right)$. The two low-energy conformers are shown in $\mathbf{4}$

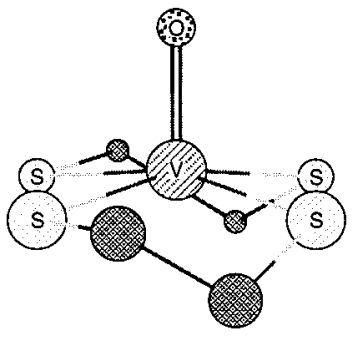

$4 a$

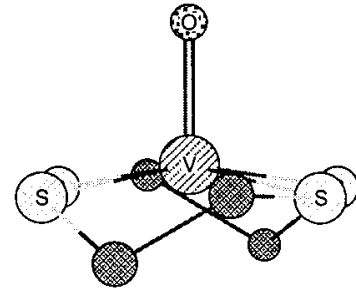

$4 b$ (heavy atoms only). The crystallographic structure has a crossed conformation. The correspondence between theory (4b) and experiment with respect to geometry was good with $\mathrm{RMS}_{\mathrm{ic}}=$ $\mathrm{RMS}_{\mathrm{hvy}}=0.20 \AA ; \mathrm{RMS}_{\mathrm{hvy}}=0.39 \AA$ for $\mathbf{4 a}$ and experiment. INDO calculations pointed to the crossed conformer being lower than the parallel conformer by $0.1 \mathrm{kcal} \mathrm{mol}^{-1}$. Given the close steric and electronic energy of $\mathbf{4 a}$ and $\mathbf{4 b}$ it seems likely that for these complexes, particularly in solution, both conformations are accessible.

Bis(maltolato)oxovanadium or BMOV is a potent insulin mimic. The compound has been the subject of extensive research as it has a rich coordination chemistry, forming $\mathrm{V}^{4+}$ and $\mathrm{V}^{5+}$ derivatives. ${ }^{25}$ Caravan et al. have labeled BMOV a "potential breakthrough in the treatment of diabetes mellitus." A molecular dynamics search of 174 structures yielded five unique conformers, three in which the oxo occupies a basal 

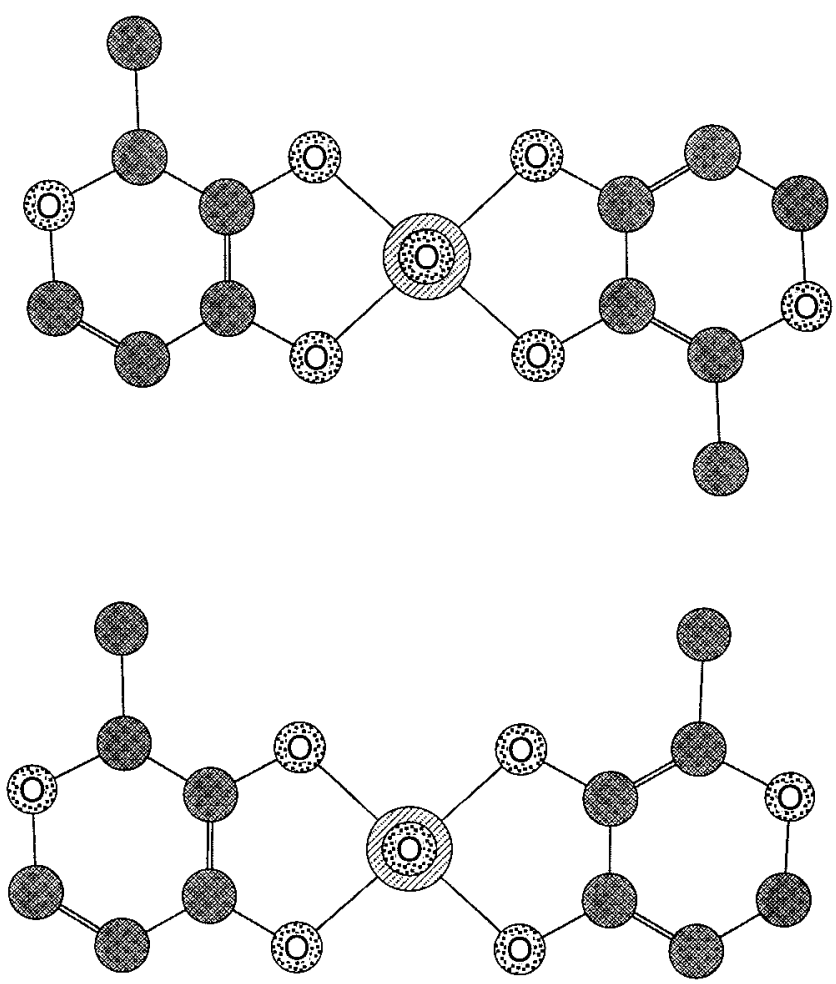

Figure 2. Syn and anti conformers of BMOV.

position $\left(\mathrm{O}=\mathrm{V}-\mathrm{lp} \approx 90^{\circ}\right.$ as in $\left.\mathbf{1 a}\right), \mathbf{5 a}$, and two in which the oxo is apical $\left(\mathrm{O}=\mathrm{V}-\mathrm{lp} \approx 180^{\circ}\right.$ as in $\left.\mathbf{1 b}\right), \mathbf{5 b}$. Steric energies

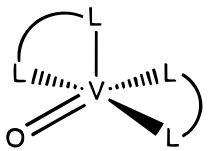

$5 a$

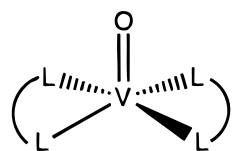

$5 b$ for the 5 conformers covered a narrow range from 13.42 to 13.57 $\mathrm{kcal} \mathrm{mol}{ }^{-1}$, with the lowest energy conformer having a basal oxo. Geometries within each group differed in relative positions of the maltolate methyls. The expected geometries with apical oxos were only $0.08 \mathrm{kcal} \mathrm{mol}^{-1}$ higher in energy than the lowest energy structure found. For conformers with an apical oxo there were two near degenerate conformers in which the methyl groups are either syn $\left(\mathbf{5 b}\right.$-anti, $\left.E_{\text {steric }}=13.497 \mathrm{kcal} \mathrm{mol}^{-1}\right)$ or anti (5b-syn, $\left.E_{\text {steric }}=13.504 \mathrm{kcal} \mathrm{mol}^{-1}\right)$, Figure 2, supporting experimental deductions regarding the existence of both isomers in solution. ${ }^{25}$ The agreement between the MM-predicted geometry for BMOV (5b-anti) was good: $\mathrm{RMS}_{\mathrm{ic}}=0.19 \AA$, $\mathrm{RMS}_{\text {hvy }}=0.21 \AA$.

Apart from $\left[\mathrm{V}^{4+} \mathrm{O}\left(\mathrm{SCH}_{2} \mathrm{CH}_{2} \mathrm{~S}\right)_{2}\right]^{2-}$ and $\mathrm{BMOV}, \mathrm{V}^{4+}-$ oxos studied with coordination number 5 include $\left(\mathrm{K}^{+}\right)_{2}\left[\mathrm{~V}^{4+} \mathrm{O}\right.$ (catecholate) $\left.)_{2}\right]^{2-} \cdot 2 \mathrm{H}_{2} \mathrm{O},{ }^{26 \mathrm{a}}\left[\mathrm{V}^{4+} \mathrm{O}(\text { acac })_{2}\right],{ }^{26 \mathrm{~b}}\left[\mathrm{~V}^{4+} \mathrm{O}\right.$ (porphyrin) $],{ }^{26 \mathrm{c}}$ and $\left[\mathrm{V}^{4+} \mathrm{O}(\right.$ acen $){ }^{26 \mathrm{~d}}$ In each case, a conformational search yielded only two structures similar to $\mathbf{5 a}$ and $\mathbf{5 b}$. The $\mathrm{RMS}_{\mathrm{hvy}}$ values ( $0.15 \AA$ for the first three examples) for the MMpredicted $\mathbf{5 b}$ structure demonstrate good agreement with experiment. The $\mathrm{RMS}_{\text {ic }}$ values were $0.18,0.19$, and $0.22 \AA$ for the catecholate, acac, and porphyrin complexes, respectively, showing that good modeling of the inner coordination sphere was also obtained. The vanadyl complex with the tetradentate acen ligand proved more challenging. Description of the inner coordination sphere was comparable to other $\mathrm{L}_{4} \mathrm{~V}^{4+} \mathrm{O}$ complexes, $\mathrm{RMS}_{\mathrm{ic}}=0.22 \AA$. Theory-experiment agreement degraded noticeably when all heavy atoms were included in

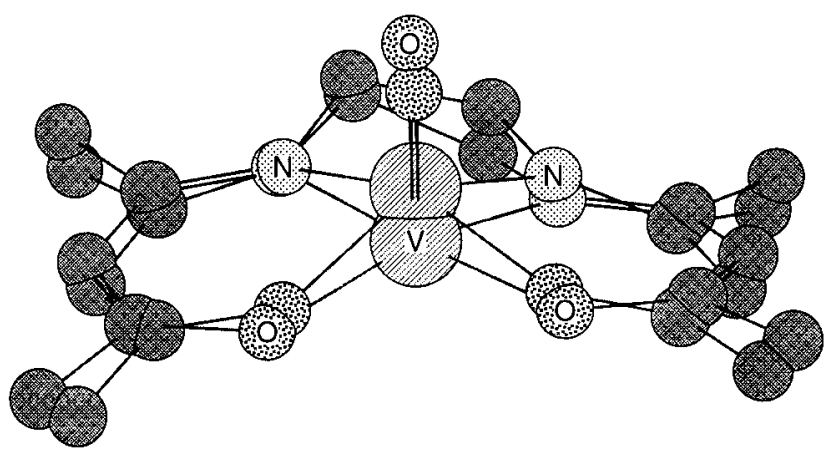

Figure 3. Overlay of MM-predicted and X-ray structures of $\left[\mathrm{V}^{4+} \mathrm{O}\right.$ (acen)].

TABLE 2: Comparison of Experimental and Predicted Structures

\begin{tabular}{|c|c|c|c|}
\hline & {$\left[\mathrm{V}^{4+} \mathrm{O}(\right.$ salen $\left.)\right]$} & {$\left[\mathrm{V}^{5+} \mathrm{O}(\text { salen })\right]^{+}\left[\mathrm{ClO}_{4}\right]^{-}$} & $\begin{array}{c}\text { VO(salen) } \\
\text { MM structure }\end{array}$ \\
\hline \multicolumn{4}{|c|}{ Bond Lengths $^{a}(\AA)$} \\
\hline $\mathrm{V}=\mathrm{O}$ & 1.59 & 1.58 & 1.61 \\
\hline $\mathrm{V}-\mathrm{O}$ & 1.92 & $1.80 \pm .01$ & 1.98 \\
\hline $\mathrm{V}-\mathrm{N}$ & 2.05 & $2.08 \pm .01$ & 2.17 \\
\hline \multicolumn{4}{|c|}{ Bond Angles (deg) } \\
\hline $\mathrm{O}=\mathrm{V}-\mathrm{O}$ & $110 \pm 3$ & $103 \pm 2$ & 100 \\
\hline $\mathrm{O}=\mathrm{V}-\mathrm{N}$ & $105 \pm 2$ & $95 \pm 1$ & 91 \\
\hline $\mathrm{O}-\mathrm{V}-\mathrm{O}$ & $87 \pm 1$ & 106 & 101 \\
\hline $\mathrm{N}-\mathrm{V}-\mathrm{N}$ & 78 & 77 & 76 \\
\hline $\mathrm{O}-\mathrm{V}-\mathrm{N}$ & 87 and $144 \pm 4$ & 85 and $156 \pm 1$ & 90 and $161 \pm 4$ \\
\hline
\end{tabular}

the comparison, $\mathrm{RMS}_{\mathrm{hvy}}=0.34 \AA$, Figure 3. Analysis of overlay indicated that although both "wings" of acen were modeled accurately, it was the folding angle between them that results in a large $\mathrm{RMS}_{\mathrm{hvy}}$.

As with the other five coordinate vanadyls like BMOV, two structures (akin to $\mathbf{5 a}$ and $\mathbf{5 b}$ ) are sterically feasible for $\left[\mathrm{V}^{4+} \mathrm{O}\right.$ (catecholate $\left.)_{2}\right]^{2-},\left[\mathrm{V}^{4+} \mathrm{O}(\mathrm{acac})_{2}\right]$, and $\left[\mathrm{V}^{4+} \mathrm{O}\right.$ (porphyrin) $]$, particularly if the coligands are bidentate like BMOV and acac. Except for the tetradentate macrocycle $\left[\mathrm{V}^{4+} \mathrm{O}\right.$ (porphyrin)], 5a and $\mathbf{5} \mathbf{b}$ were obtained regardless of which structure was used to initiate the MD simulation. Although conformers $\mathbf{5 a}$ and 5b may possess similar steric energies, experimental evidence and electronic structure analyses clearly pointed to a preference for the latter. ${ }^{16}$ Indeed, INDO calculations showed a great preference for $\mathbf{5} \mathbf{b}$ over $\mathbf{5 a}$ for $\left[\mathrm{V}^{4+} \mathrm{O}\left(\mathrm{SCH}_{2} \mathrm{CH}_{2} \mathrm{~S}\right)_{2}\right]^{2-}(22 \mathrm{kcal}$ $\left.\mathrm{mol}^{-1}\right), \mathrm{BMOV}\left(>40 \mathrm{kcal} \mathrm{mol}^{-1}\right),\left[\mathrm{V}^{4+} \mathrm{O}(\text { catecholate })_{2}\right]^{2-}(19$ $\left.\mathrm{kcal} \mathrm{mol}^{-1}\right),\left[\mathrm{V}^{4+} \mathrm{O}(\mathrm{acac})_{2}\right]\left(17 \mathrm{kcal} \mathrm{mol}^{-1}\right)$, and $\left[\mathrm{V}^{4+} \mathrm{O}-\right.$ (porphyrin)] $\left(18 \mathrm{kcal} \mathrm{mol}^{-1}\right)$. Hence, a combination of MM and semiempirical quantum mechanical methods is a powerful technique for rapid identification and steric and electronic analysis of conformational and coordination isomers for transition metal complexes.

Oxos of the Schiff base salen $\left(N^{\prime}, N^{\prime}\right.$-disalicylidene-ethylenediamine) were interesting since examples are known with $\mathrm{V}^{4+}$ or $\mathrm{V}^{5+} .{ }^{27,28}$ Table 2 compares pertinent bond lengths and bond angles for $\left[\mathrm{V}^{4+} \mathrm{O}(\right.$ salen $\left.)\right],\left[\mathrm{V}^{5+} \mathrm{O}(\text { salen })\right]^{+}$, and MM-predicted $\mathrm{VO}$ (salen). The similarity of the salen X-ray structures with each other and also with the MM geometry was very interesting. In general, $\mathrm{V}-\mathrm{L}$ bond lengths for the MM geometry were closer to those for the experimental vanadyl structure, while MMpredicted $\mathrm{L}-\mathrm{V}-\mathrm{L}$ bond angles were in better agreement with $\left[\mathrm{V}^{5+} \mathrm{O}(\text { salen })\right]^{+}$. The overlay of predicted vs experimental structure of $\left[\mathrm{V}^{5+} \mathrm{O}(\text { salen })\right]^{+}$had an $\mathrm{RMS}_{\mathrm{ic}}=0.17 \AA$ and $\mathrm{RMS}_{\mathrm{hvy}}$ 
$=0.29 \AA$. For $\mathrm{V}^{4+} \mathrm{O}$ (salen), there are two inequivalent molecules in the unit cell; $\mathrm{RMS}_{\mathrm{ic}}=0.04 \AA$ and $\mathrm{RMS}_{\mathrm{hvy}}=0.13$ $\AA$ for these. An overlay of the MM-optimized structure of VO(salen) yields $\mathrm{RMS}_{\mathrm{ic}}=0.23 \AA, \mathrm{RMS}_{\mathrm{hvy}}=0.24 \AA$ and $\mathrm{RMS}_{\mathrm{ic}}$ $=0.24 \AA$, and $\mathrm{RMS}_{\mathrm{hvy}}=0.31 \AA$ for each of the inequivalent molecules in the unit cell of $\mathrm{V}^{4+} \mathrm{O}$ (salen).

2.4. Coordination Number 6, Oxidation Number $5+$. $\mathrm{V}^{5+-}$ oxos are most commonly found with coordination numbers of six. The vanadate ion $(+5$ oxidation state) was found to be a potent inhibitor of $\mathrm{Na}^{+}, \mathrm{K}^{+}-$ATPase. $^{2,3}$ Although research indicates that the vanadate ion is reduced to vanadyl and bound to proteins in the body, compounds with biogenic ligands such as amino acids remain of interest in the biochemistry of vanadium. $^{29}$

Three $\left[\mathrm{VO}_{2} \text { (oxalate) }\right]^{-3}$ structures have been reported, each with a cis dioxo geometry. ${ }^{30}$ Calculations yielded two structures: cis or trans $\mathrm{O}=\mathrm{V}=\mathrm{O}$. The cis structure was predicted by $\mathrm{MM}$ to be $0.6 \mathrm{kcal} \mathrm{mol}^{-1}$ lower in steric energy. INDO calculations at the MM-optimized geometries also pointed to an electronic preference (by $59 \mathrm{kcal} \mathrm{mol}^{-1}$ ) for cis over trans. The agreement between the MM-predicted structure and the most recent experimental structure ${ }^{30 \mathrm{c}}$ was excellent: $\mathrm{RMS}_{\mathrm{ic}}=$ $0.10 \AA$ and $\mathrm{RMS}_{\mathrm{hvy}}=0.17 \AA$.

Riley et al. studied vanadium complexes as model spectroscopic probes of the binding site of transferrin. ${ }^{28}$ Two oxovanadium(V)ethylenebis((o-hydroxyphenyl)glycine) structures were reported; ${ }^{28,31}$ an overlay of the structures suggests they are identical. After $500 \mathrm{MM} / \mathrm{MD}$ simulated annealing cycles, the force field predicted 10 unique conformations. Two of these ( $6 \mathbf{a}$ and $\mathbf{6 b}, \mathrm{H}$ atoms removed for clarity) were $\approx 1 \mathrm{kcal} \mathrm{mol}^{-1}$

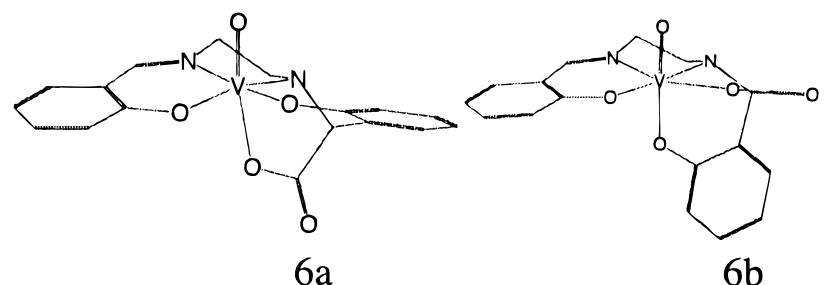

more stable than the rest, with the former $\left(E_{\text {steric }}=32.41 \mathrm{kcal}\right.$ $\left.\mathrm{mol}^{-1}\right)$ slightly more stable $\left(E_{\text {steric }}=32.62 \mathrm{kcal} \mathrm{mol}^{-1}\right)$. In comparison with the most recent crystal structure, ${ }^{28}$ the MMpredicted lowest energy structure (6a) had an $\mathrm{RMS}_{\mathrm{ic}}=0.17 \AA$ and $\mathrm{RMS}_{\mathrm{hvy}}=0.19 \AA\left(\mathrm{RMS}_{\mathrm{hvy}}=2.21 \AA\right.$ for $\left.\mathbf{6 b}\right)$. The structure consistent with experiment (6a) was predicted to be $2 \mathrm{kcal} \mathrm{mol}^{-1}$ lower in energy than $\mathbf{6 b}$ by INDO calculations.

The crystal structure of $\left[\mathrm{VO}(\right.$ sal-L-ala $\left.)\left(\mathrm{OCH}_{3}\right)\left(\mathrm{CH}_{3} \mathrm{OH}\right)\right]$ and its catalytic activity for asymmetric sulfide oxidation was reported. ${ }^{32}$ A search of 500 conformations yielded 38 unique low-energy conformations ranging from $E_{\text {steric }}=20.7 \mathrm{kcal} \mathrm{mol}^{-1}$ to $22.8 \mathrm{kcal} \mathrm{mol}^{-1}$. The six lowest energy structures have the oxo ligand trans to the pyridine nitrogen. Among the unique conformations was a structure (eighth lowest in energy) with the alanine methyl endo to the oxide $\left(7 \mathbf{a}, E_{\text {steric }}=21.7 \mathrm{kcal}\right.$

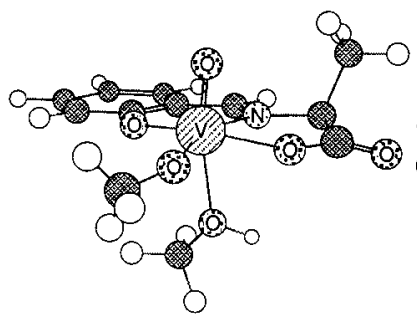

$7 \mathrm{a}$

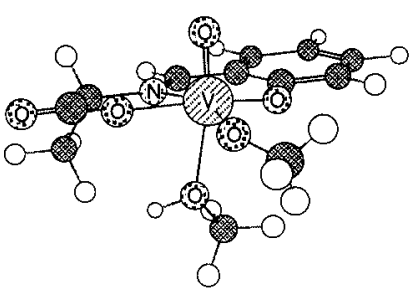

$7 \mathrm{~b}$

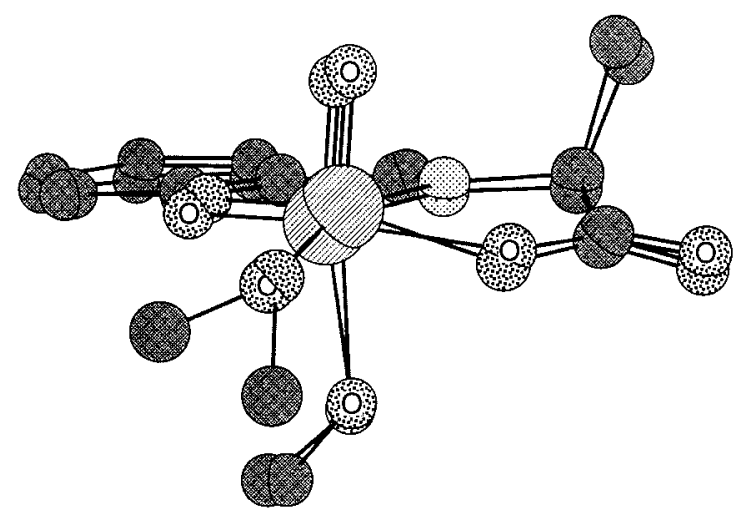

Figure 4. Overlay of MM-predicted and X-ray structure of [VO(salL-ala) $\left.\left(\mathrm{OCH}_{3}\right)\left(\mathrm{CH}_{3} \mathrm{OH}\right)\right]$.

$\mathrm{mol}^{-1}$ ) and a related structure (twelfth lowest in energy) with an exo methyl $\left(\mathbf{7 b}, E_{\text {steric }}=21.6 \mathrm{kcal} \mathrm{mol}^{-1}\right)$. The near degeneracy of exo and endo isomers is consistent with the suggestion by Nakajima that both exist in solution. ${ }^{32}$ Conformer 7a differs from the crystal mainly in the $\mathrm{O}-\mathrm{C}$ dihedral of the OMe ligand, Figure 4, as seen by the very good agreement for the inner coordination sphere $\left(\mathrm{RMS}_{\mathrm{ic}}=0.13 \AA\right.$ ) while $\mathrm{RMS}_{\mathrm{hvy}}$ $=0.35 \AA$. Furthermore, $\mathrm{RMS}_{\mathrm{hvy}}$ is $0.20 \AA$ when the methoxide $\mathrm{C}$ was ignored. $\mathrm{RMS}_{\mathrm{hvy}}$ is $1.96 \AA$ for the lowest energy conformer found $\left(E_{\text {steric }}=20.7 \mathrm{kcal} \mathrm{mol}^{-1}\right)$. INDO calculations indicate that $\mathbf{7 b}$ is lower in energy than $\mathbf{7 a}$ by $3 \mathrm{kcal} \mathrm{mol}^{-1}$, a reversing of the steric energy ordering. The isomer most consistent with experiment (7a) is $1.6 \mathrm{kcal} \mathrm{mol}^{-1}$ above the conformation with the lowest electronic energy.

A third structure in this group that was investigated is $\mathrm{V}^{5+}$. ( salimh)(catecholate), salimh $=$ [4-(2-salicylideneaminato)ethyl]imidazole. $^{33}$ A search of 95 conformers resulted in two lowenergy conformers: $E_{\text {steric }}=39.15 \mathrm{kcal} \mathrm{mol}^{-1}(\mathbf{8 a})$ and $E_{\text {steric }}$ $=39.65 \mathrm{kcal} \mathrm{mol}^{-1}(\mathbf{8 b})$ differing in conformation about the

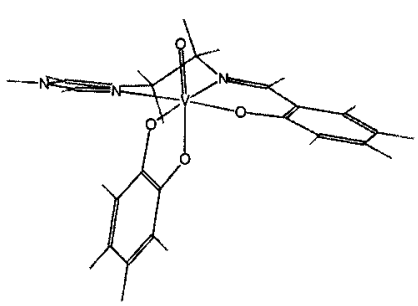

$8 \mathrm{a}$

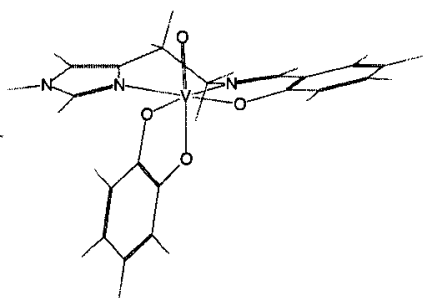

$8 b$ ethylene spacer leading to the imidazole. MM optimization starting from the crystal structure coordinates leads to $\mathbf{8 b}$. The agreement between the MM-predicted geometry for $\mathbf{8 b}$ and experiment is reasonable for the inner coordination sphere $\left(\mathrm{RMS}_{\mathrm{ic}}=0.21 \AA\right)$, but less so for the entire set of heavy atoms: $\mathrm{RMS}_{\mathrm{hvy}}=0.36 \AA\left(\mathrm{RMS}_{\mathrm{hvy}}=0.62 \AA\right.$ for $8 \mathbf{b} \mathrm{vs}$ experiment). The overlap of the two individual chelates is good $\left(\mathrm{RMS}_{\text {VOsalimh }}=0.13 \AA\right.$, $\left.\mathrm{RMS}_{\text {VOcat }}=0.22 \AA\right)$, indicating that it is the relative orientation of the two ligands which is the cause of the high $\mathrm{RMS}_{\mathrm{hvy}}$. INDO calculations support the MM prediction that $8 \mathbf{a}$ is lower in energy than $\mathbf{8 b}\left(\Delta E_{\mathrm{INDO}}(\mathbf{8 a}-\mathbf{8 b})\right.$ $=3 \mathrm{kcal} \mathrm{mol}^{-1}$ ). Hence, both MM and QM results are at odds with the X-ray structure, although the small steric and electronic energy differences would suggest caution in terms of predicting one or the other as the preferred conformation.

The structure of $\mathrm{Li}^{+}\left[\mathrm{V}^{5+}(\mathrm{O})_{2}(S \text {-peida })\right]^{-} \cdot 2 \mathrm{H}_{2} \mathrm{O}$ has been reported, $S$-peida $=(S)$-[[1-(2-pyridyl)ethyl]iminodiacetate $]{ }^{34}$ An MM/MD search of 500 conformations yielded 7 unique 


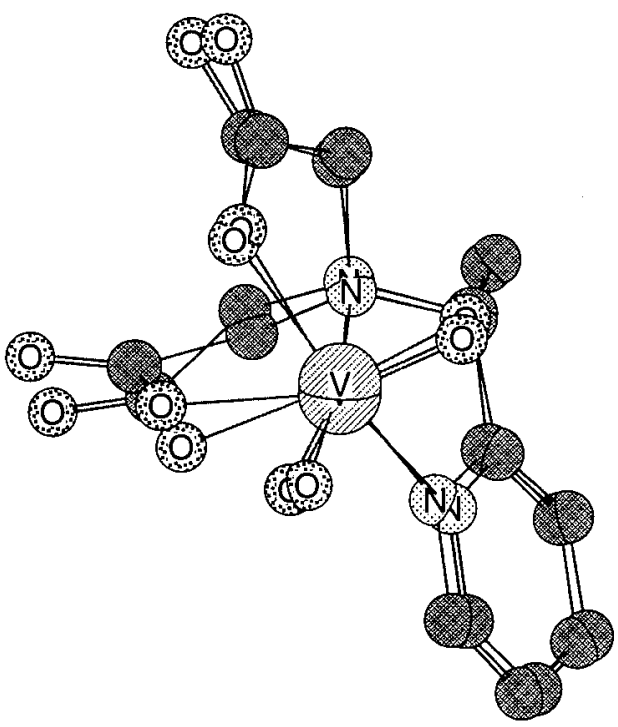

Figure 5. Overlay of MM-predicted and X-ray structure of $\left[\mathrm{V}^{5+}(\mathrm{O})_{2^{-}}\right.$ $(S \text {-peida) }]^{-}$.

conformers from $E_{\text {steric }}=16.85 \mathrm{kcal} \mathrm{mol}^{-1}$ to $E_{\text {steric }}=20.21$ $\mathrm{kcal} \mathrm{mol}^{-1}$. The MM-predicted lowest energy conformer is more than $1 \mathrm{kcal} \mathrm{mol}^{-1}$ lower in steric energy than the next most stable conformation. Geometry optimization starting from the crystal coordinates results in an MM-optimized structure for $\left[\mathrm{V}^{5+}(\mathrm{O})_{2}(S \text {-peida })\right]^{-}$that has $E_{\text {steric }}=16.85 \mathrm{kcal} \mathrm{mol}^{-1}$ and is identical with that obtained from the MM/MD simulated annealing search. Comparison of the MM-predicted lowest energy conformer and the X-ray structure yields $\mathrm{RMS}_{\mathrm{hvy}}=0.30$ $\AA$ (reducing to $0.24 \AA$ without the carbonyl oxygens on acetate arms) and $\mathrm{RMS}_{\mathrm{ic}}=0.22 \AA(0.13 \AA$ without one coordinated carboxylate $\mathrm{O})$. An overlap of the MM-predicted lowest energy conformer and the X-ray structure is shown in Figure 5.

3. Comparison with Semiempirical Quantum Calculations. There has long been interest in developing semiempirical methods for transition metals given the success of these techniques with organic molecules. ${ }^{6,23}$ These methods are computationally efficient and can be routinely used for the study of very large compounds. The same transition metal properties that hinder force field development also conspire against semiempirical methods. Perhaps the greatest success to date has been achieved with techniques such as extended Hückel and Zerner's INDO parametrization ${ }^{23}$ for description of electronic structure and (in the case of the latter) electronic spectra. Structural prediction is challenging, and various workers have focused on extending well-known parametrizations such as PM3 to d-block complexes. ${ }^{35}$ The techniques are new, and it is of interest to gauge their predictive ability, particularly in relation to other methods. We compare below MM and PM3 geometries for $\mathrm{L}_{n} \mathrm{VO}$. MM geometries were used to provide starting guesses for PM3 optimizations as it is not our purpose to evaluate them for conformational analysis although this is an interesting extension.

Table 3 organizes $\mathrm{RMS}_{\text {ic }}$ and $\mathrm{RMS}_{\mathrm{hvy}}$ for MM- and PM3predicted $\mathrm{L}_{n} \mathrm{VO}$ geometries. Convergence problems precluded analysis of $\left[\mathrm{V}^{4+}(\mathrm{O})(\right.$ salen $\left.)\right]$, although its analogue $\left[\mathrm{V}^{5+}(\mathrm{O})\right.$ (salen) $]^{+}$was amenable to PM3 calculations. Hence, the former is not included in our analysis. A comparison of predictive ability vs experiment showed similar success for the inner coordination sphere. The range of $\mathrm{RMS}_{\mathrm{ic}}$ was somewhat narrower for MM $(0.06-0.22 \AA)$ than that for PM3 $(0.05-$ $0.29 \AA$ ). However, $\mathrm{RMS}_{\text {ic }}$ for MM was slightly higher (average $=0.16 \AA$ ) than for PM3 (average $=0.14 \AA$ ). In terms of the
TABLE 3: Comparison of Predicted and Experimental Geometries

\begin{tabular}{|c|c|c|c|c|}
\hline structure $^{a}$ & $\begin{array}{c}\mathrm{RMS}_{\mathrm{ic}}{ }^{b} \\
\mathrm{MM}\end{array}$ & $\begin{array}{c}\mathrm{RMS}_{\mathrm{hvy}}{ }^{b} \\
\mathrm{MM}\end{array}$ & $\begin{array}{l}\mathrm{RMS}_{\mathrm{ic}}{ }^{b} \\
\mathrm{PM} 3\end{array}$ & $\begin{array}{c}\mathrm{RMS}_{\mathrm{hvy}}{ }^{b} \\
\text { PM3 }\end{array}$ \\
\hline$\left[\mathrm{V}^{5+}(\mathrm{O})_{2}(\mathrm{dpc})\right]^{-}$ & 0.13 & 0.11 & 0.09 & 0.09 \\
\hline$\left[\mathrm{V}^{5+}(\mathrm{O})_{2}(\mathrm{~F})(\text { oxalate })\right]^{2-}$ & 0.15 & 0.13 & 0.13 & 0.14 \\
\hline$\left[\mathrm{V}^{4+} \mathrm{O}\left(\mathrm{OH}_{2}\right) 5\right]^{2+}$ & 0.10 & 0.10 & 0.14 & 0.14 \\
\hline$\left[\mathrm{V}^{4+} \mathrm{O}(\text { oxalate })_{2}(\mathrm{~F})\right]^{3-}$ & 0.10 & 0.15 & 0.14 & 0.23 \\
\hline$\left[\mathrm{V}^{4+}(\mathrm{O})(\mathrm{dpc})\left(\mathrm{OH}_{2}\right)_{2}\right]$ & 0.06 & 0.08 & 0.12 & 0.12 \\
\hline$\left[\mathrm{V}^{4+} \mathrm{O}\left(\mathrm{SCH}_{2} \mathrm{CH}_{2} \mathrm{~S}\right)_{2}\right]^{2-}$ & 0.20 & 0.20 & 0.10 & 0.15 \\
\hline bis(maltolato)oxovanadium & 0.19 & 0.21 & 0.11 & 0.15 \\
\hline$\left[\mathrm{V}^{4+} \mathrm{O}(\text { catecholate })_{2}\right]^{2-}$ & 0.18 & 0.15 & 0.09 & 0.18 \\
\hline$\left[\mathrm{V}^{4+} \mathrm{O}(\mathrm{acac})_{2}\right]$ & 0.19 & 0.15 & 0.14 & 0.20 \\
\hline$\left[\mathrm{V}^{4+} \mathrm{O}\right.$ (porphyrin) $]$ & 0.22 & 0.15 & 0.05 & 0.09 \\
\hline$\left[\mathrm{V}^{4+} \mathrm{O}(\right.$ acen $\left.)\right]$ & 0.22 & 0.34 & 0.19 & 0.32 \\
\hline$\left[\mathrm{V}^{5+} \mathrm{O}(\text { salen })\right]^{+}$ & 0.17 & 0.29 & 0.29 & 0.36 \\
\hline$\left[\mathrm{V}^{4+} \mathrm{O}(\right.$ salen $\left.)\right] \mathrm{A}^{c}$ & 0.24 & 0.31 & $d$ & $d$ \\
\hline$\left[\mathrm{V}^{4+} \mathrm{O}(\right.$ salen $\left.)\right] \mathrm{B}^{c}$ & 0.23 & 0.24 & $d$ & $d$ \\
\hline $\begin{array}{l}\text { vanadium(V)ethylenebis( }(o- \\
\text { hydroxyphenyl)glycine) }\end{array}$ & 0.17 & 0.19 & 0.29 & 0.36 \\
\hline$\left[\mathrm{VO}_{2}(\text { oxalate })_{2}\right]^{3-}$ & 0.10 & 0.17 & 0.12 & 0.24 \\
\hline$\left[\mathrm{VO}(\right.$ sal-L-ala $\left.)\left(\mathrm{OCH}_{3}\right)\left(\mathrm{CH}_{3} \mathrm{OH}\right)\right]$ & 0.15 & 0.35 & 0.11 & 0.51 \\
\hline $\mathrm{V}^{5+}$ (salimh)(catecholate) & 0.21 & 0.36 & 0.13 & 0.50 \\
\hline
\end{tabular}

${ }^{a}$ Abbreviations for the different ligands are given in the text. ${ }^{b} \mathrm{RMS}_{\mathrm{ic}}$ and $\mathrm{RMS}_{\mathrm{hvy}}$ are given in angstroms and defined in the text. ${ }^{c} \mathrm{~A}$ theoryexperiment comparison is given with each of the two inequivalent molecules, termed molecule A and molecule B by Riley et al. ${ }^{28}$ found in the unit cell of $\mathrm{V}^{4+} \mathrm{O}$ (salen). ${ }^{d}$ Convergence problems precluded the analysis of $\left[\mathrm{V}^{4+} \mathrm{O}\right.$ (salen) $]$ by the PM3 methods.

overall geometry, the MM force field outperforms the PM3 method for the complexes studied: average $\mathrm{RMS}_{\mathrm{hvy}}=0.20 \AA$ $(\mathrm{MM})$, average $\mathrm{RMS}_{\mathrm{hvy}}=0.24 \AA$ (PM3). The range of $\mathrm{RMS}_{\mathrm{hvy}}$ for test complexes was much less for MM $(0.08-0.36 \AA)$ than PM3 (0.09-0.51 $\AA$ ). PM3 parameters for V were obtained by interpolation from reported values for $\mathrm{Ti}$ and $\mathrm{Cr}$; more detailed parametrization efforts will likely increase theory-experiment agreement. However, this preliminary study indicates that the PM3 method warrants further research for routine study of large transition metal complexes. One could envision the use of MM to quickly probe the conformational space of a coordination complex, with the best candidates being further refined using semiempirical techniques. A few of the best candidates could then be analyzed with high-level, quantum calculations resulting in a quick and accurate analysis of realistically sized transition metal complexes in a short period of time.

\section{Summary and Conclusions}

A molecular mechanics study of $\mathrm{V}$-oxos, important biochemical and catalytic entities, is reported. A summary of important conclusions from this work are listed below.

(1) The coordination chemistry of vanadium is very diverse. A force field for vanadium-oxos was developed and tested with a variety of complexes with coordination numbers of 5 or 6 and formal oxidations states of $4+$ or $5+$ on the metal. In this research soft and hard ligands were studied, as were ligands coordinated through single, multiple, and dative bonds. Despite the diversity of vanadium coordination chemistry, generally good modeling is achieved in a fraction of the time with considerably less computational resources. Although modeling of effects such as the trans influence are troublesome for MM, such interactions are likewise challenging for quantum methods. Geometries consistent with experimental structures were found not only for rigid complexes such as $\left[\mathrm{V}^{5+}(\mathrm{O})_{2}(\text { oxalate })_{2}\right]^{3-}$, but also for more flexible compounds such as $\left[\mathrm{V}^{5+}(\mathrm{O})_{2}(S \text {-peida })\right]^{-}$.

(2) The combination of molecular mechanics and semiempirical quantum mechanical calculations provides an effective 
and efficient tool for analysis of the steric and electronic energy differences between isomers. Examples of this technique were demonstrated by compounds such as $\left[\mathrm{V}^{4+} \mathrm{O}\left(\mathrm{SCH}_{2} \mathrm{CH}_{2} \mathrm{~S}\right)_{2}\right]^{2-}$ and $\left.\left[\mathrm{V}^{4+} \mathrm{O} \text { (catecholate }\right)_{2}\right]^{2-}$. Although MM predictions found two isomers possessing similar steric energies, quantum calculations demonstrated a clear preference for the geometry which is consistent with experiment.

(3) $\mathrm{The} \mathrm{L}_{4} \mathrm{~V}^{4+} \mathrm{O}$ and $\mathrm{L}_{5} \mathrm{~V}^{5+} \mathrm{O}$ groups were emphasized given their prevalence and importance. In general, the predictive ability was superior for the former structural motif. For example, $\mathrm{V}^{5+} \mathrm{O}$ (salimh)(catecholate) posed difficulty with the force field parameters in that the MM-predicted geometry was inconsistent with experiment. The quantum results were also at odds with the crystal structure. However, small steric and electronic energy differences between conformers such as these should be taken into account and the best two or three conformers submitted to calculation at higher levels of theory.

(4) Complexes such as $\left[\mathrm{V}^{4+} \mathrm{O}\left(\mathrm{H}_{2} \mathrm{O}\right)_{5}\right]^{2-}$ that have a considerable trans influence may be problematic since this was not modeled in the force field. Approaches to dealing with this problem have been addressed. ${ }^{7 \mathrm{~d}, 36}$ To include separate cis and trans ligating types would require more extensive parametrization; generality would be lost. Alas, modeling the strong trans influence of the oxo remains a challenge for MM and quantum methods.

(5) In this work, as in related research, comparisons are drawn with solid-state structures as this represents the overwhelming majority of experimental data used to calibrate structural prediction. MM/MD calculations predicted near degenerate endo and exo isomers that exist in solution for $\mathrm{VO}$ (sal-L-ala)$\left.\left(\mathrm{OCH}_{3}\right)\left(\mathrm{CH}_{3} \mathrm{OH}\right)\right]$ as well as the syn and anti structures thought to be present in solution for bis(maltolato)oxovanadium(IV). These results suggest that validated MM force fields can be an important tool for probing the structure of metal complexes in solution where most catalytic and biochemical reactions take place.

(6) Molecular mechanics can provide quick and accurate structural prediction. This information is often the starting point in computer-aided design and analysis. One motivation in studying $\mathrm{V}-$ oxos is that they provide the potential for many conformational and coordination geometry isomers. This research has demonstrated the ability of a simple MM model to yield reliable results. Predicting structures of $\mathrm{V}$-oxos, consistent with experiment, despite their chemical diversity, is encouraging for the application of MM to transition metal chemistry. The level of agreement for structural prediction is comparable to that obtained by computationally intensive methods in much less time. Therefore, MM may be used to quickly screen out unlikely structural types and conformations.

Acknowledgment. The authors thank the National Science Foundation (CHE-9614346) for support of this research and Professor Gerard Parkin and Tina Trnka (Columbia University) for their help in obtaining structural information on vanadium oxo compounds. The assistance of Melissa Beaugrand (University of Memphis) in performing some of the computations is also gratefully acknowledged. L.L.S. thanks the University of Memphis and the Society of Cosmetic Chemists for scholarship support.

Supporting Information Available: MM-optimized geometries for systems studied and force field parameters are given (27 pages). See any current masthead page for ordering and Internet access instructions.

\section{References and Notes}

(1) Coulston, G. W.; Bare, S. R.; Kung, H.; Birkeland, K.; Bethke, G. K.; Harlow, R.; Herron, N.; Lee, P. L. Science 1997, 275, 191.

(2) Shechter, Y.; Shisheva, A.; Lazar, R.; Libman, J.; Shanzer, A. Biochemistry 1992, 31, 2063.

(3) Chasteen, N. D. Structure and Bonding; Springer: Berlin, 1983; Vol. 53, p 105.

(4) Research by Makinen and co-workers provides an excellent example of the use of vanadyl complexes as a probe of the structure and dynamics of biological molecules using experimental techniques such as nuclear magnetic resonance (NMR), electron paramagnetic resonance (EPR), and electron nuclear double resonance (ENDOR) spectroscopy, e.g., Jiang, F. S.; Makinen, M. W. Inorg. Chem. 1995, 34, 1736.

(5) Cundari, T. R.; Sisterhen, L. L.; Stylianopoulos, C. L. Inorg. Chem. 1997, 36, 4029.

(6) Spartan (version 4.1) User's Guide; Wavefunction, Inc.: Irvine, CA, 1995

(7) (a) Hay, B. P. Inorg. Chem. 1991, 30, 2786. (b) Allured, V. S.; Kelly, C. M.; Landis, C. R. J. Am. Chem. Soc. 1991, 113, 1. (c) Rappé, A. K.; Colwell, K. S.; Casewit, C. J. Inorg. Chem. 1993, 32, 3438. (d) Mayo, S. L.; Olafson, B. D.; Goddard, N. A., III. J. Phys. Chem. 1990, 94, 8877. (e) Hay, B. P. Coord. Chem. Rev. 1993, 126, 177. (f) Comba, P. Coord. Chem. Rev. 1993, 123, 1.

(8) Cundari, T. R.; Fu, W.; Klinckman, T. R.; Moody, E. W.; Slavin, L. L.; Snyder, L. A.; Sommerer, S. O. J. Phys. Chem. 1996, 100, 18057.

(9) Schmidt, M. W.; Baldridge, K. K.; Boatz, J. A.; Jensen, J. H.; Koseki, S.; Matsunaga, N. M.; Gordon, M. S.; Nguyen, K. A.; Su, S.; Windus, T. L.; Elbert, S. T. J. Comput. Chem. 1993, 14, 1347.

(10) Krauss, M.; Stevens, W. J.; Basch, H.; Jasien, P. G. Can. J. Chem. 1992, 70,612

(11) Cundari, T. R.; Gordon, M. S. Coord. Chem. Rev. 1996, 87, 87.

(12) Boatz, J. A.; Gordon, M. S. J. Phys. Chem. 1986, 7, 385.

(13) Allinger, N. L.; Burkert, U. Molecular Mechanics; American Chemical Society: Washington, DC, 1982

(14) Chem 3D Plus User's Manual; Cambridge Scientific: Cambridge, 1992.

(15) Cundari, T. R.; Moody, E. W.; Sommerer, S. O. Inorg. Chem. 1995, 34,5989 .

(16) Nugent, W. A.; Mayer, J. M. Metal Ligand Multiple Bonds; Wiley: New York, 1988.

(17) Nuber, B.; Weiss, J.; Wieghardt, K. Z. Naturforsch., B., 1978, 33, 265.

(18) Rieskamp, H.; Mattes, R. Z. Anorg. Allg. Chem. 1976, 419, 193. 1761.

(20) Benson, M. T.; Cundari, T. R.; Lim, S. J.; Nguyen, H. D.; PierceBeaver, K. J. Am. Chem. Soc. 1994, 116, 3955.

(21) Rieskamp, H.; Mattes, R. Z. Naturforsch., B 1976, 31, 537.

(22) (a) Bersted, B. H.; Belford, R. L.; Paul, I. C. Inorg. Chem. 1968 ,

7, 1557. (b) Sundheim, A.; Mattes, R. Z. Naturforsch., B 1993, 48, 125.

(23) Zerner's INDO/1 parametrization has been shown to accurately describe the electronic structure of transition metal complexes, although it is generally less reliable for structural prediction. Anderson, W. P.; Edwards, W. D..; Zerner, M. C. Inorg. Chem. 1986, 25, 2728. INDO calculations were run using HyperChem (version 4.5, Hypercube, Inc., 1994).

(24) (a) Wiggins, R. W.; Huffman, J. C.; Christou, G. C. J. Chem. Soc., Chem. Commun. 1983, 1313. (b) Money, J. K.; Huffman, J. C.; Christou, G. C. Inorg. Chem. 1985, 24, 3297.

(25) Caravan, P.; Gelmini, L.; Glover, N.; Herring, F. B.; Li, H.; McNeill, J. H.; Rettig, S. J.; Setyawati, I. K.; Shuter, E.; Sun, Y.; Tracey, A. G.; Yuen, U. G.; Orvig, C. J. Am. Chem. Soc. 1995, 117, 12759.

(26) (a) Cooper, S. W.; Koh, Y. B.; Raymond, K. N. J. Am. Chem. Soc 1982, 104, 5092. (b) Three structures have been reported for $\mathrm{VO}(\mathrm{acac})_{2}$, acac $=$ acetylacetonate; our comparison is with the structure reported by Shuter et al. Shuter, E.; Retting, S. J.; Orvig, C. Acta Crystallogr. 1995 51, 12. Dodge, R. P.; Templeton, D. H. Zalkin, A. J. Chem. Phys. 1961, 35, 55. Hon, P.; Belford, R. L.; Pfluger, C. E. J. Chem Phys. 1965, 43, 3111. (c) The macrocycle reported by Drew et al. is etioporphyrin. Pendent groups were removed in the calculations to give the parent porphyrin dianion, $\mathrm{C}_{20} \mathrm{~N}_{4} \mathrm{H}_{12}{ }^{2-}$. Drew, M. G. B.; Mitchell, P. C. H.: Scott, C. E. Inorg. Chim. Acta 1984, 82, 63. (d) acen $=N, N^{\prime}$-ethylene bis(acetoneiminato). Bruins, D.; Weaver, D.; Inorg. Chem. 1970, 9, 130.

(27) Bonadies, J. A.; Butler, W. M.; Pecoraro, V. L.; Carrano, C. J. Inorg. Chem. 1987, 26, 1218.

(28) Riley, P. E.; Pecoraro, V. L.; Carrano, C. J.; Bonadies, J. A.; Raymond, K. N. Inorg. Chem. 1986, 25, 154.

(30) (a) Scheidt, W. R.; Tsai, C.; Hoard, J. L. J. Am. Chem. Soc. 1971, 93, 3867. (b) Drew, R. E.; Einstein, F. W. B.; Gransden, S. E. Can. J. 
Chem. 1974, 52, 2184. (c) Stomberg, R. Acta Chem. Scand. 1986, A40, 168.

(31) Pecoraro, V. L.; Bonadies, J. A.; Marrese, C. A.; Carrano, C. J. J. Am. Chem. Soc. 1984, 106, 3360.

(32) Nakajima, K.; Kojima, M.; Toriumi, K.; Saito, J.; Fujita, J. Bull. Chem. Soc. 1989, 62, 760.

(33) Cornman, C. R.; Kampf, J.; Pecoraro, V. L. Inorg. Chem. 1981, $31,1992$.
(34) Kojima, A.; Okazaki, K.; Ooi, S.; Saito, K. Inorg. Chem. 1983, 22,1168 .

(35) An application of the PM3 method to chromium complexes has been reported by Ignatov and co-workers. Ignatov, S. K.; Razuvaev, A. G.; Kokorev, V. N. J. Phys. Chem. 1996, 100, 6354.

(36) Comba, P.; Hambley, T. W. Molecular Modeling of Inorganic Compounds; VCH: Weinheim, 1995. 